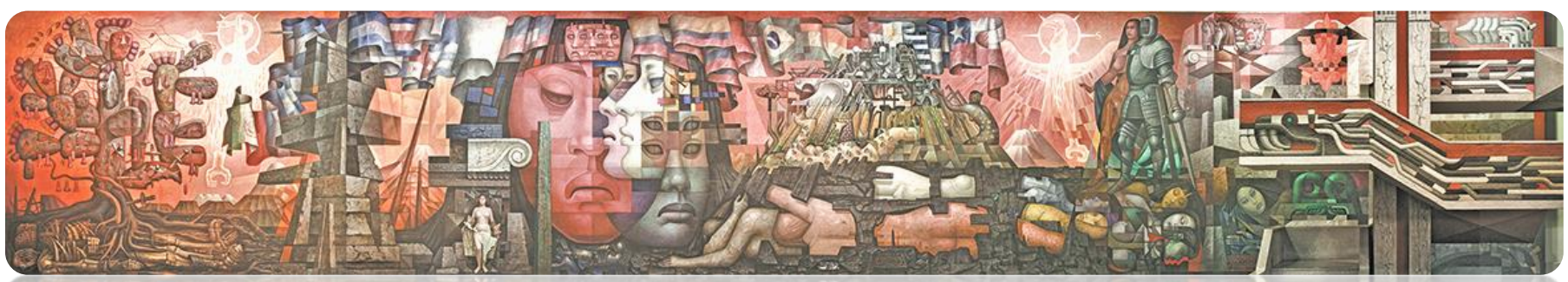

Rev. Hist., N²8, vol. 2, Julio-Diciembre 2021: 271-293

ISSN 0717-8832

https://doi.org/10.29393/RH28-34GSPF20034

\title{
La gran sequía de 1968: efectos sociopolíticos y crisis de la democracia en Chile*
}

The great drought of 1968: socio-political effects and crisis of democracy in Chile

\author{
Pablo Camus** \\ Fabián Jaksic***
}

\section{RESUMEN}

Este artículo estudia la sequía de 1968 como un fenómeno climático severo asociado con la crisis política y social que irrumpió en Chile a fines de esa y la siguiente década. A partir del análisis de bibliografía, prensa escrita y crónicas de sesiones del Senado, se pondera el factor climático como un aspecto relevante en el desarrollo de los acontecimientos políticos, sociales y económicos del período. Argumentamos que la sequía de 1968 no se trató de un evento climático aislado de su contexto histórico que solo afectó la producción agrícola, sino que se estructuró también como un factor precipitante que agudizó los conflictos sociopolíticos detonados por el proceso de Reforma Agraria en Chile, incidiendo finalmente en la crisis de la democracia en la década de 1970.

Palabras clave: Sequía de 1968, reforma agraria, agricultura chilena, escasez de precipitaciones, crisis sociopolítica

\footnotetext{
* Proyecto financiado a través del Fondecyt 1180537 y del Programa ANID PIA/BASAL FB0002, al CAPES, Pontificia Universidad Católica de Chile.

** Doctor en Historia, P. Universidad Católica de Chile. Profesor del Instituto de Historia de la Pontificia Universidad Católica de Chile. ORCID: https://orcid.org/0000-0002-9705-6320. Correo electrónico: pcamusg@uc.cl

*** Doctor en Zoología, Universidad de California-Berkeley, EE.UU. Profesor del Departamento de Ecología Pontificia Universidad Católica de Chile. ORCID: https://orcid.org/0000-0003-0098-0291. Correo electrónico: fjaksic@bio.puc.cl
} 


\begin{abstract}
This article aims at studying the 1968 drought as a severe climatic phenomenon associated with the political and social crisis that irrupted in Chile toward the end of that and the following decade. Based on analysis of bibliography, written press, and chronicles of Senate sessions, consideration is given to the climatic factor as a relevant aspect in the development of the political, social, and economic events of the period. We argue that the 1968 drought did not constitute an isolated climatic event that only affected agricultural production, but also acted as a precipitating element of the social and political conflicts triggered by the Agrarian Reform process, which eventually resulted in a democracy crisis in Chile during the 1970s.
\end{abstract}

Key words: Drought, agrarian reform, Chilean agriculture, precipitation shortage, socio-political crisis

Recibido: enero 2021

Aceptado: junio 2021

\title{
Introducción
}

La década de 1960 estuvo marcada por múltiples propuestas de cambio sociocultural, tanto a nivel nacional como internacional, que tensionaron las relaciones entre los distintos sectores y actores sociopolíticos. Tras el derrumbe del iluminismo, que no había logrado alcanzar las transformaciones impulsadas por el pensamiento ilustrado $\mathrm{y}$, después de dos guerras mundiales, se hacía imperioso avanzar en la concreción de las ideas originarias como igualdad, libertad y fraternidad. A nivel internacional esto se expresó en una serie de rebeldías, movimientos, protestas y propuestas en contra del predominio del capital en las relaciones políticas y económicas, además de las discriminaciones tanto raciales como de género y socioculturales ${ }^{1}$.

En un mundo dividido ideológicamente por la Guerra Fría y tras una cierta estabilidad desde el fin de la Segunda Guerra Mundial, este ciclo se gatillaría en América Latina con la Revolución Cubana. Así, por ejemplo, intelectuales tan influyentes como Jean Paul Sartre y Simone de Beauvoir se reunieron en Cuba con Ernesto «Che» Guevara en 1960. Inicialmente admirados por la Revolución y sugiriendo la idea de una emancipación inconclusa, los centros del poder intelectual occidental fueron el verdadero germen del movimiento social que caracterizó la

\footnotetext{
${ }^{1}$ Seidman, Michael. 2018. La Revolución Imaginaria. París 1968: Estudiantes y Trabajadores en el Mayo Francés, Madrid, Alianza Editorial. Servan Schreiber, Jean Jacques. 1968. El despertar de Francia. mayo-junio 1968. Plaza \& Janés. Abadía Quintero, Carolina y Antonio Echeverry Pérez. 2020. De mayos del 68 a la Cali del 70. Ensayos en perspectiva latinoamericana de una década que transformó al mundo, Barcelona, Programa Editorial UNIVALLE. Pellegrini, Mario. 2008. La imaginación al poder, Buenos Aires, Argonauta.
} 
década de 1960. Las universidades congregaron a una serie de cerebros críticos, como los de la Escuela de Frankfurt en Alemania, de los intelectuales marxistas británicos y de las diversas corrientes de pensamiento existencialista y posmoderno surgidas en Francia ${ }^{2}$. Con sus propuestas críticas dieron contenido a las ideas de los individuos que clamaban por el fin de los privilegios y el establecimiento de las igualdades y libertades, tal como lo había establecido el ideario de la modernidad ilustrada. Asimismo, otras naciones iniciarían sus propios caminos hacia el establecimiento de una sociedad igualitaria, que trascendiera las injusticias inherentes a una sociedad agraria tradicional, y a un sistema capitalista de producción liderado por Estados Unidos. Las protestas contra la guerra de Vietnam, el movimiento por los derechos civiles, la Primavera de Praga, el movimiento estudiantil parisino de mayo de 1968 y la masacre de Tlatelolco fueron expresiones visibles de los malestares derivados de los débiles resultados del proyecto ilustrado 3 .

Esta contradicción comenzaría a manifestarse cada vez con mayor fuerza en Chile a partir de la elección presidencial de 1958, en la cual se expresaron con claridad los conflictos sociales, políticos y económicos. La Democracia Cristiana, escindida del Partido Conservador, comenzaba a ocupar un espacio político entre las fuerzas de derecha y las de izquierda, fenómeno que fue denominado por Mario Góngora como la "era de las planificaciones globales", el cual dividió al país en tres tercios excluyentes entre sí ${ }^{4}$. La polarización existente en la sociedad civil se expresó también en el surgimiento de diversos grupos políticos como Patria y Libertad, el MAPU y el MIR, además de movimientos universitarios que clamaban por reformar el sistema para alcanzar mayores grados de igualdad y libertad ${ }^{5}$.

En este contexto de crisis sistémica global, en la cual las disputas entre los distintos agentes políticos y sociales parecían indisolubles, irrumpe en nuestro país una de las sequías más extraordinarias que se hayan observado desde que se tienen registros confiables de precipitaciones, según se evidencia en el gráfico 1. Hasta ahora los análisis realizados sobre el período en general, y la Reforma Agraria en particular, no han considerado suficientemente la escasez de precipitaciones. Por tanto, y reparando con especial acento en una hipótesis escasamente pesquisada en Chile, nuestro interés radica en indagar sobre las siguientes interrogantes: ¿De qué manera influyó la sequía extrema en el desarrollo de los

\footnotetext{
2 Iggers, Georg G. 2012. La Historiografía del Siglo XX: Desde la Objetividad Científica al Desafío Posmoderno. México D. F., Fondo De Cultura Económica. Jay, Martin. 1974. La Imaginación Dialéctica: Historia de la Escuela De Frankfurt y el Instituto de Investigación Social (1923-1950). Madrid, Taurus.

${ }^{3}$ Adorno, Theodor y Max Horkheimer. 1998. Dialéctica de la llustración: fragmentos filosóficos, Madrid, Trotta.

${ }^{4}$ Góngora, Mario. 1985. Ensayo histórico sobre la noción de Estado en Chile, Santiago, Ed. Universitaria.

${ }^{5}$ Ramón, Armando de. 2015. Historia de Chile: desde la invasión incaica hasta nuestros días (1500-2000), Santiago de Chile, Catalonia Ltda.; Sagredo, Rafael. 2014. Historia mínima de Chile, Madrid, España, Turner Publicaciones S.L.; Collier, Simon y Sater, William. 1999. Historia de Chile, Cambridge University Press, Madrid; Salazar, Gabriel y Julio Pinto. 2014. Historia contemporánea de Chile, Santiago, LOM Ediciones. Winn, Peter. 2013. La Revolución Chilena. Santiago, Chile, LOM Ediciones.
} 
acontecimientos políticos y sociales de finales de la década de 1960? ¿Contribuyó al descontento y la polarización social la escasez de precipitaciones, la baja en la producción de alimentos y de las expectativas que se tenían en torno a la Reforma Agraria?

Gráfico 1. Precipitaciones en Santiago de Chile 1824-2020 (en milímetros)

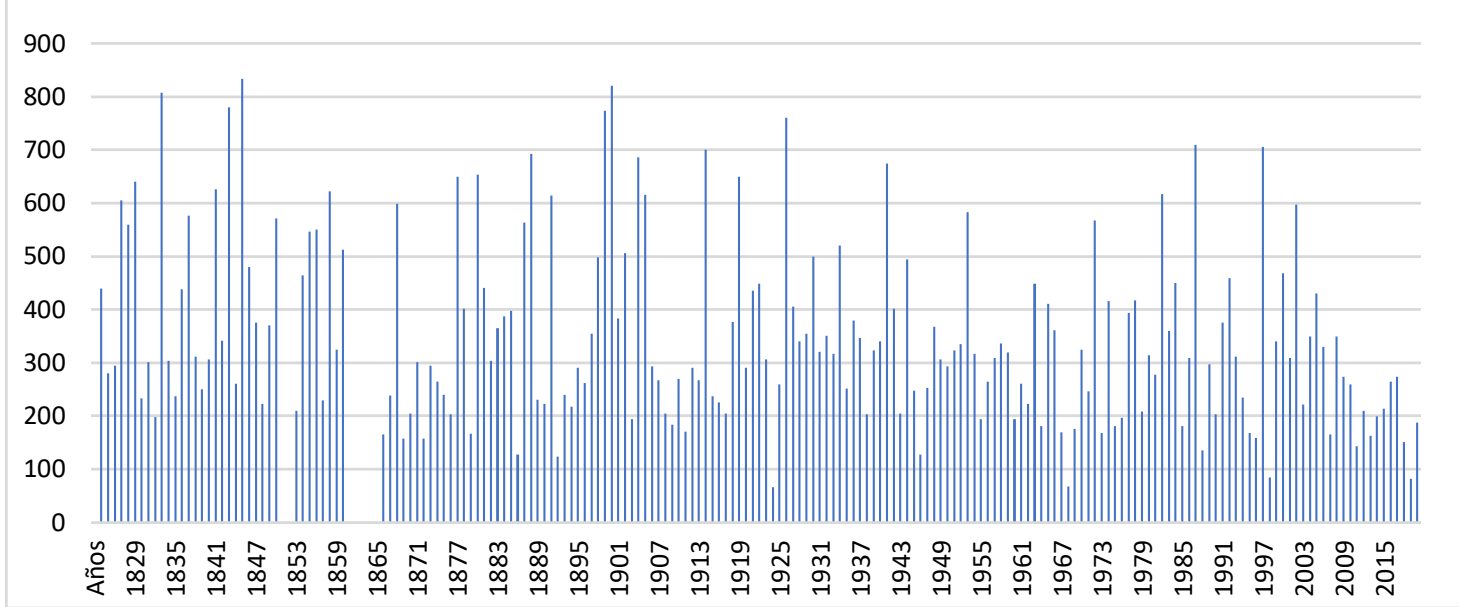

Fuentes: Sociedad Nacional de Agricultura (Chile), Anuario Estadístico de la República de Chile y Dirección Meteorológica de Chile.

A partir de este planteamiento no queremos desmerecer otros factores que incidieron en la crisis sociopolítica, cruciales por lo demás para comprender la época, sino que buscamos complementar ese análisis a través de un estudio de las condiciones ambientales que rodearon a esa crítica coyuntura. Existe una vasta literatura sobre la Reforma Agraria en sus distintas dimensiones -que no es el caso detallar acá-, pero no se ha abordado ni ponderado el factor climático como un elemento más de la crisis política y social de la época6 ${ }^{6}$. Así, a través del estudio de las fuentes del período, intentaremos dilucidar si este componente pudo o no influir en el desarrollo de los acontecimientos sociales, políticos y económicos y en la crisis que se

\footnotetext{
${ }^{6}$ A raíz de los cincuenta años de la Reforma Agraria surgieron una serie de publicaciones. Véanse por ejemplo Olea, Jorge. 2017. "Latifundio y territorio: reflexiones en torno a la reforma agraria en Colchagua, 1960-1973", en Polis, Revista Latinoamericana, № 47, Santiago, pp. 83-106; Canales, Manuel, Jorge Razeto, René Valenzuela, (coordinadores). 2018. Casta y sumisión: Chile a 50 años de la Reforma Agraria, Santiago, Social Ediciones; Consejo Asesor Campesino. 2018, Con nuestra letra: relatos campesinos de la Reforma Agraria chilena escritos por puño y letra de sus protagonistas, Santiago de Chile, Consejo Asesor Campesino, Región Metropolitana; INDAP. Chonchol, Jacques [y otros]. 2017. Reforma agraria, Santiago, Editorial Aún Creemos en los Sueños; Rojas, Álvaro y Paula Manríquez, Editores. 2017. Reforma Agraria 50 años después: origen y desarrollo del proceso, Talca, Chile. Editorial Universidad de Talca; Bengoa, José. 2016. Reforma agraria y revuelta campesina: seguido de un homenaje a los campesinos desaparecidos, Santiago de Chile, LOM Ediciones; Oszlak, Oscar. 2016. La trama oculta del poder: reforma agraria y comportamiento político de los terratenientes chilenos, 1958-1973. Santiago Chile, LOM Ediciones. Gac, Daniella; Flores, Daniel; Thezá, Marcel. 2017. "Reformas agrarias en América Latina y Chile: lecciones aprendidas sobre la controversia de la propiedad de la tierra". Polis, Revista Latinoamericana, № 47, Santiago, pp. 5-11.
} 
desencadenó a fines de la década de 1960 e inicios de la siguiente. En relación a los materiales y métodos empleados en esta investigación, hemos recurrido a bibliografía y fuentes disponibles con el objeto de aproximarnos a la opinión de los distintos actores sociopolíticos de la época. Con miras a este objetivo, analizamos las discusiones parlamentarias de los diarios de sesiones legislativas, además de distintos medios de prensa, que reportaron los calamitosos efectos de la sequía.

\section{El enfrentamiento ideológico, el triunfo de Eduardo Frei Montalva y la reforma agraria}

Con la llegada de los años sesenta, los movimientos sociales cuestionaron el orden económico y social global. La agitación social, el desenfreno de las costumbres, las ansias de cambio, la cultura de masas y la rebeldía de los jóvenes imprimieron un sello particular a la década. En los países desarrollados, los movimientos críticos abogaban por mayores espacios de democracia e igualdad, rebelándose contra las discriminaciones y las prohibiciones de todo tipo. En los países subdesarrollados y en América Latina en particular, las críticas al orden existente se centraban más bien en las desigualdades sociales, la miseria y la pobreza, aspectos que demostraban que las promesas de la modernidad no se estaban cumpliendo, por lo que se comenzaron a exigir transformaciones profundas como la reforma agraria. En el caso de Chile, también se advierte la emergencia de movimientos sociales de todo tipo presionando tanto por las transformaciones sociales y económicas como también por el cambio cultural y de las costumbres?.

En estas circunstancias se desarrolló la elección presidencial de 1964, ocasión en que los sectores de derecha decidieron no presentar candidato para evitar el triunfo de la alianza de izquierda encabezada por Salvador Allende. De este modo, Eduardo Frei Montalva fue elegido con un $56 \%$ del total de votos emitidos, inaugurando la Revolución en Libertad. En su programa de gobierno Frei Montalva propuso una serie de reformas estructurales como la redistribución del ingreso, la participación popular, la "chilenización" del cobre y la profundización de la Reforma Agraria, iniciada tímidamente por las recomendaciones de la Alianza para el Progreso durante el gobierno de Jorge Alessandri ${ }^{8}$.

Pese al apoyo de la derecha, tras la elección de Frei Montalva la sociedad chilena agudizó sus contradicciones y la constante agitación social aceleró las movilizaciones y un creciente descontento se expresó en diversas manifestaciones callejeras, huelgas, ocupaciones de fábricas y tomas de terreno urbanos y agrícolas. El ascenso de las acciones tendientes a

\footnotetext{
7 Torres Dujisin, Isabel. 2009. "La década de los sesenta en Chile: la utopía como proyecto", en Historia Actual online (HAOL), N¹9, Cádiz, pp.139-149. Reyes Del Villar, Soledad. 1999. La Revolución Cultural de los años 60' vista a través del Mayo Francés y del Movimiento Estudiantil Chileno, Santiago, Chile.

${ }^{8}$ Sexto Mensaje Presidencial de S.E. Don Eduardo Frei Montalva al inaugurar el periodo de Sesiones Ordinarias del Congreso Nacional, 21 de mayo de 1970. 1970. Santiago, Presidencia de la República, Departamento de Publicaciones.
} 
subvertir el orden establecido generó la reacción de los sectores más conservadores que intentaron detener la espiral de protesta, originándose una confrontación que trascendió todos los ámbitos de la sociedad.

La aprobación de una ley de Reforma Agraria más radical, el impulso de la sindicalización campesina, la puesta en marcha de la promoción popular y el aumento del gasto público incorporaron a nuevos sectores a la participación política y generaron cada vez mayores expectativas en torno a la necesidad de realizar cambios más estructurales. Los partidos, el parlamento y la negociación política dejaron de tener el protagonismo de antaño, abriendo mayores espacios a la acción directa expresada en marchas callejeras, concentraciones, huelgas y protestas vinculadas a los distintos actores sociales.

En el ámbito rural, el gobierno mantenía elevadas expectativas tras la aprobación de la nueva ley de Reforma Agraria, anhelando un importante incremento de la productividad, y de las condiciones de vida y dignidad de los trabajadores agrícolas. Destacando los logros alcanzados en su período presidencial, en mayo de 1970 Eduardo Frei Montalva hizo el siguiente recuento del proceso de Reforma Agraria: "en estos años se han expropiado hasta la fecha en que hablo, 1.224 fundos con una superficie de 3.200.000 hás. Esta superficie está compuesta de 265.000 hás. de riego y 2.935 .000 de secano" ${ }^{\prime}$.

Sin embargo, al proyecto se oponían los grandes agricultores, mientras que los campesinos exigían mayor celeridad. En medio de la agitación y el ambiente conflictivo prevaleciente, las tomas de latifundios se incrementaron sustancialmente de 12 en 1968 a 111 en 1969 y a 285 en 1970. Esto acentuó en forma significativa la polarización y la beligerancia de todos los actores políticos y sociales, dado el significado social, económico y cultural que implicaba la gran propiedad agrícola en el imaginario nacional ${ }^{10}$. Pero en pocos meses, la insubordinación de inquilinos y peones estalló en el Valle Central. Entre el verano de 1967 y 1968 se produjeron más de 1.400 huelgas y los llamados a la calma no prosperaron. Los políticos y los técnicos no contaron con la ira campesina acumulada por siglos. Así, la ley de Reforma y la ley de Sindicalización Campesina radicalizaron en pocos meses la situación de los campos. De este modo, el predominio de los hacendados "se rompió como un vidrio en mil pedazos"11.

En estas circunstancias, y según los registros oficiales de la Dirección Meteorológica de Chile, 1968 fue uno de los años más secos del siglo XX en Chile. En este sentido, la revista Topaze consideraba que el país estaba "viviendo una catástrofe nacional cuyos efectos son peores que los del terremoto de 1960, con la diferencia que la capital de la república y en muchas latitudes

\footnotetext{
9 Ídem, p. 35.

${ }^{10}$ Correa, Sofía et al. 2001. Historia del siglo XX chileno, Santiago, Ed. Sudamericana.

${ }^{11}$ Bengoa, José. 2015. Historia rural de Chile central: Tomo II. Crisis y ruptura del orden hacendal, Santiago, LOM Ediciones, p. 289.
} 
de su territorio la gente no se da cuenta del drama que la sequía significa" ${ }^{12}$. Este fenómeno climático, que el presidente Frei Montalva calificó como un "terremoto silencioso», causó profundos y graves daños en la producción agropecuaria poniendo más tensión en un territorio ya sacudido por la reforma agraria y las transformaciones sociopolíticas que se encontraban en marcha ${ }^{13}$. A juicio de Frei Montalva, la sequía había golpeado decisivamente la expansión del PGB (Producto Geográfico Bruto). En su último mensaje presidencial, y contrario a lo que algunos estimaban, indicó en este sentido que:

"para medir el desarrollo no debería considerarse el crecimiento del PGB, porque involucra el hecho circunstancial de los efectos del alto precio del cobre. Pero también yo podría observar que si el precio del cobre nos ha favorecido, ha habido otros factores desfavorables, también circunstanciales, como la sequía prolongada, en algunas zonas por más de cuatro años, que han representado un factor de baja considerable de la producción, en general. Recordemos que en 1969 la producción agrícola decreció en un 18\% como resultado de las condiciones climáticas" ${ }^{14}$.

Gráfico 2. Precipitaciones en Santiago de Chile 1960-1969 (en milímetros)

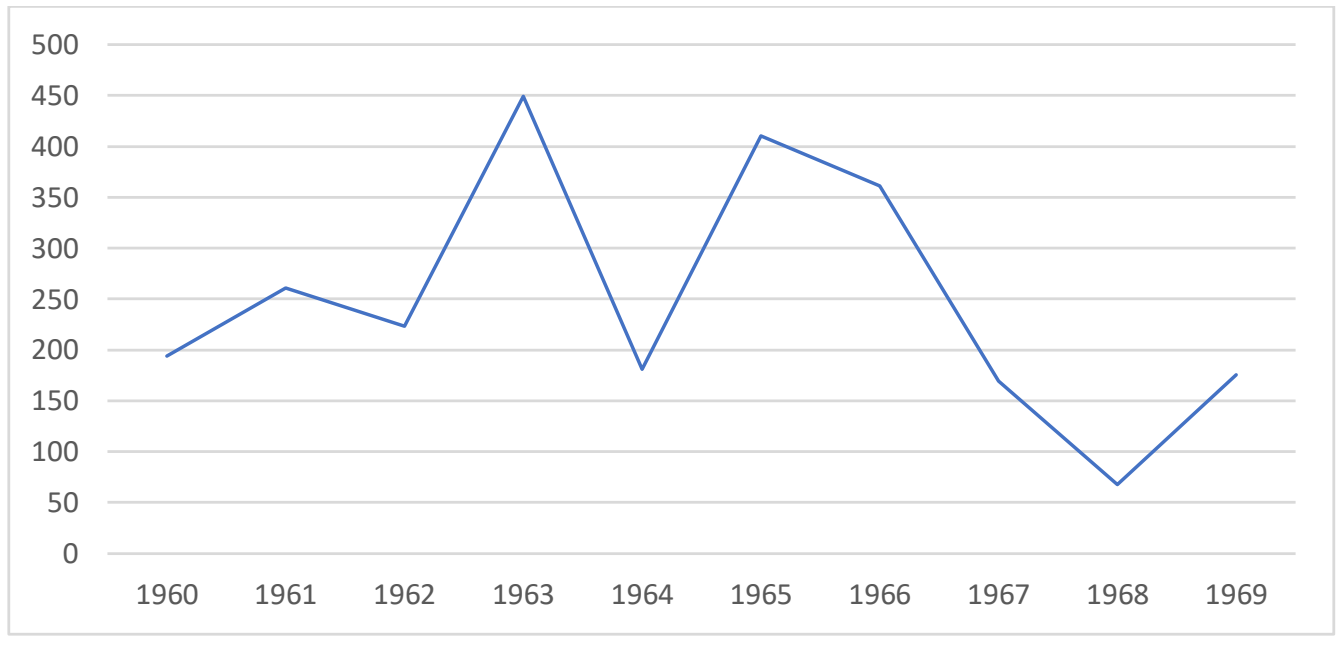

Fuente. Dirección Meteorológica de Chile.

12 "La sequía", Topaze, 19 de julio de 1968, p.3.

${ }^{13}$ Gazmuri, Cristián et al. 1996. Eduardo Frei Montalva: (1911-1982), México, Fondo de Cultura Económica.

${ }^{14}$ Sexto Mensaje Presidencial de S.E. Don Eduardo Frei Montalva.1970, p. 65. 


\section{La sequía de 1968 y sus impactos políticos, sociales y económicos en el agro nacional}

El geógrafo Pedro Cunill realizó una evaluación de los daños provocados por la sequía de 1968 en su libro Geografía de Chile ${ }^{15}$. De acuerdo con los antecedentes que recopiló tras la catástrofe, la zona comprendida entre las provincias de Atacama y Ñuble fue la más afectada por la sequía. El déficit pluviométrico registrado durante 1968 fue cuantioso, sin precedentes en décadas. Siguiendo las cifras de las principales ciudades de norte a sur, en Copiapó este índice se empinó al 100\%; en La Serena al 73\%; en Ovalle al 71\%; en Quintero al $81 \%$; en Valparaíso al 80\%; en Santiago al 81\%; en Rancagua al 75\%; en Curicó al 63\%; en Constitución al $60 \%$; en Linares al $55 \%$ y, por último, en Chillán al 51\%. A ello se agregaba la ausencia o escasez de nevazones en el sector andino, mientras que en el resto de país las pluviosidades también habían sido bastante menores que las habituales, alcanzando un déficit de $50 \%$ en Concepción, 47\% en Los Ángeles, $40 \%$ en Victoria, 43\% en Temuco y 49\% en Valdivia.

Numerosas localidades y asentamientos rurales fueron asolados por la escasez de agua. En Placilla de Peñuelas, por ejemplo, donde vivían "como en un dormitorio proletario de Valparaíso, más de cinco mil personas, excluyendo a los niños nacidos después del último censo, la sequía que azotaba al país había creado un problema pavoroso a aquellos modestos pobladores, porque los pozos que abastecían las necesidades de agua de esa comunidad estaban secos" ${ }^{16}$. Como consecuencia de lo anterior "el tifus y las afecciones colibacilares podían diezmar a esa gente" ${ }^{17}$, y en general a la población de los numerosos asentamientos humanos rurales de la Zona Central de Chile. Para afrontar los problemas en el abastecimiento de agua potable, el gobierno desarrolló un programa de emergencia destinado a mejorar los sistemas de captación y asegurar el normal abastecimiento urbano que abarcó a 30 ciudades. Así, el gobierno tuvo que adquirir camiones aljibes y estanques de material plástico para suministrar agua a localidades pequeñas y villorrios rurales ${ }^{18}$.

La escasez de precipitaciones afectó especialmente a la agricultura, la ganadería, la generación de electricidad, la minería y el agua para usos domésticos e industriales. En la Sociedad Minera El Teniente la menor producción de energía eléctrica y de agua para los procesos productivos, impidió el funcionamiento a capacidad plena de los equipos industriales de molienda y concentración de minerales, viéndose disminuida la producción de cobre estimada para 1968 en más de la mitad $^{19}$.

\footnotetext{
${ }^{15}$ Cunill, Pedro. 1971. Geografía de Chile, Santiago, Editorial Universitaria.

${ }^{16}$ Congreso Nacional de Chile. Diario de Sesiones del Senado, Sesión 24ạ , en martes 17 de diciembre de 1968, p. 1231.

17 Ídem.

${ }^{18}$ Cunill, Pedro. 1971. Geografía de Chile, Santiago, Editorial Universitaria.

19 La Nación, 10 de agosto de 1968, p. 3.
} 
Asimismo, la sequía perjudicó enormemente a la agricultura, afectando de forma directa la producción de viñas, arroz, maíz, leguminosas, hortalizas y remolacha. En la zona más afectada por la sequía, las superficies bajo riego disminuyeron en alrededor de $44 \%$. Sin embargo, una de las áreas más afectadas fue la agricultura de secano, la cual no contó con las lluvias necesarias para la siembra. Hubo que suministrar víveres a 20.000 familias de pequeños campesinos, ocupándolos en obras de mejoramiento de caminos u otras obras públicas. La situación se mantuvo en 1969 para los campesinos de las provincias de Atacama y Coquimbo, especialmente en las áreas de los comuneros, donde se registró un importante abandono de los campos para emigrar a los núcleos urbanos. Adicionalmente, las pérdidas en la ganadería fueron notables, constatándose una alta mortandad en los animales por falta de forraje, particularmente en los rebaños caprinos y ovinos del Norte Chico y sectores de la Cordillera de la Costa. Hubo que transportar gratuitamente 80.000 cabezas de ganado de la zona de sequía a las regiones sureñas y también el gobierno bonificó el transporte de forraje a las zonas $\operatorname{afectadas}^{20}$.

En O'Higgins y Colchagua, Antonio Molfino, representante del sindicato de empleadores agrícolas de la costa norte de Colchagua y constituido en defensa de los agricultores de las comunas de Marchigüe, Pichilemu, Estrella y Rosario de Lo Solís, informaba al senador Hermes Ahumada la gravísima crisis por la que atravesaba la ganadería de la zona costera de Colchagua. Por otra parte, el senador Ahumada indicaba que, según informes del señor Sergio Huerta Muñoz, ingeniero agrónomo del departamento de Santa Cruz (zona eminentemente agrícola), la falta de lluvias había traído como consecuencia bajas temperaturas que perjudicaban enormemente las plantaciones de cítricos, en términos que ya se había perdido $15 \%$ de la producción. Del mismo modo, "la producción de leche había mermado hasta llegar a límites inconcebibles, lo cual había redundado, igual que en el caso de la carne, en alzas de precios". Por otra parte, las siembras no se habían podido realizar debido a la carencia de lluvias, "lo cual habrá de significar inmensos perjuicios en lo futuro" ${ }^{21}$.

A su juicio, se trataba de la mayor sequía ocurrida en los últimos 102 años. Sólo "la de 1924 era comparable a la actual", con la agravante de que jamás se había "producido idéntico fenómeno entre las provincias de O'Higgins y Linares". El déficit de agua ocasionado por la sequía en relación con el registrado en 1924 era de $90 \%$ en la zona de Valparaíso; 83\% en la de Rancagua; $75 \%$ en la de Curicó; $70 \%$ en Linares y $6 \%$ en Chillán. Más aun la situación era "inmensamente más grave en el Norte Chico, donde no ha caído un solo milímetro de lluvia, excepto en La Serena" ${ }^{22}$. Con el objetivo de evaluar las pérdidas ocasionadas por la escasez de precipitaciones, el senador Hermes Ahumada citaba un informe de los profesores Pablo

\footnotetext{
20 Ídem.

${ }^{21}$ Congreso Nacional de Chile. Diario de Sesiones del Senado, Sesión 26모, en martes 23 de julio de 1968, p. 1172.

22 Ídem.
} 
Barahona, Ernesto Fontaine y Rolf Lüders, de la Facultad de Economía de la Universidad Católica, titulado "Algunos Problemas de la Sequía y sus posibles Soluciones". El estudio calculaba en $\$ 505$ millones de escudos las pérdidas ocasionadas a las diversas producciones agrícolas, a causa de este fenómeno climático. Sin embargo, dicha estimación consideraba únicamente la zona comprendida entre las provincias de Coquimbo y Ñuble. Al quedar excluidas las pérdidas ocasionadas en las plantaciones de frutales y en los viñedos, "por eso, a ojo de buen varón, puede decirse, sin pecar de exageración, que las pérdidas totales alcanzarían a no menos de mil millones de escudos" 23 .

Efectivamente, la sequía afectó directamente las diversas actividades productivas de las provincias de Chile Central. La escasez de precipitaciones disminuyó la producción agrícola e incrementó el desempleo, la pobreza, el hambre y los conflictos sociales en un contexto ya hostil derivado de la aprobación y ejecución de la ley de Reforma Agraria y la ley de Sindicalización Campesina. La sequía de 1968, entonces, habría contribuido a una radicalización de las posiciones políticas y sociales de los distintos actores del campo chileno ${ }^{24}$.

A mediados del año siguiente, los efectos de la sequía seguían haciéndose sentir en la población de la Zona Centro-Norte. A la crisis política y social en que se hallaba envuelto el país, se sumaba la escasez de precipitaciones que se prolongaba afectando directamente las actividades económicas agrícolas, mineras y portuarias; dificultades que comenzaron a repercutir en las posibilidades de alimentación de las familias chilenas. Para dimensionar el impacto de la sequía en la producción de alimentos en Atacama y Coquimbo, según el senador Tomás Chadwick, era "necesario pensar en lo que significa la falta absoluta de lluvias con relación al millón 325 mil hectáreas que son normalmente aprovechables en la agricultura y la ganadería" 25 . Asimismo, la sequía también afectaba a los pequeños propietarios mineros, pues no había agua y los trapiches se encontraban parados. Todo lo anterior repercutía en la paralización de las actividades del puerto de Coquimbo.

De esta manera, la falta de precipitaciones había provocado una ola de cesantía y la población de las provincias ya no tenía para alimentarse "otros medios que el que se les procura en las ollas comunes. Resulta doloroso contemplar largas filas de hombres, mujeres y niños que esperan recibir el alimento que a los jefes de familia no les es posible ganar con su trabajo" ${ }^{26}$. En Ovalle, se estaban "repartiendo 37 mil raciones para suplir el ingreso en dinero que normalmente podrían obtener los trabajadores" ${ }^{27}$. En este sentido, el senador Chadwick señalaba que estaba en cuestión "la sobrevivencia en una región en la cual, por carencia de

\footnotetext{
23 Ídem, p. 1173.

24 López, Nicolás. 2017. "Un terremoto silencioso. Sequía y crisis social en el campo chileno, 1967-1969", en Seminario Simon Collier 2017, Instituto de Historia, Pontificia Universidad Católica de Chile, Santiago, p. 105.

${ }^{25}$ Congreso Nacional de Chile. Diario de Sesiones del Senado, Sesión 17ạ, en martes 15 de julio de 1969, p. 1092.

26 Ídem.

27 Ídem.
} 
agua suficiente, falta todo lo que permite subsistir al ser humano.... los hombres, mujeres y niños han debido dejar sus casas vacías para irse a agregar a las poblaciones marginales de los distintos centros urbanos" 28 .

La crisis en las provincias agrícolas, provocada por el proceso de reforma agraria y precipitada por la sequía de 1968, encendió los ánimos regionalistas y los sentimientos de identidad local. Por ejemplo, en la zona rural de Santiago, los representantes del gobierno central parecían "ignorar el drama que se cierra como siniestra mortaja sobre la ya tan castigada zona melipillana" ${ }^{29}$. Si bien, tanto la prensa local como la santiaguina criticaban el manejo que el gobierno hacía de los infortunios producidos por la sequía, la primera enfatizó los contratiempos de los agricultores, evidenciando los conflictos políticos y económicos de las provincias con el gobierno central. La gravedad de la crisis acelerada por la sequía reveló que el problema de la descentralización era económico, pero también político y social. De esta manera, dotó de contenido a las demandas de las provincias al originar un discurso que rescataba su identidad cultural y sus valores intrínsecos, en contraposición al poder que representaba la capital. Las dos visitas en helicóptero del ministro de Agricultura Hugo Trivelli, demostraban para los melipillanos el lujo y privilegios capitalinos frente al total abandono en que se hallaban las provincias en medio de la catástrofe ${ }^{30}$.

Para la región de O'Higgins, las escasas precipitaciones y sus efectos económicos, políticos y sociales se prolongaron por años. Colchagua, conocida como el "riñón de la oligarquía», concentraba a sus alrededores un buen número de los fundos de las elites nacionales, afectados por la reforma agraria y las tomas de terrenos ${ }^{31}$. Entre las actividades económicas, la producción de vino era parte esencial de su concepción de mundo y de su identidad cultural, enmarcada en una geografía particular. No obstante, en 1969 la producción de uva cayó en un $80 \%$. Producto de la sequía, ésta era pequeña y de mala calidad. Esto afectó la producción y calidad del vino, y disminuyó en forma significativa los ingresos de los viñateros y agricultores, además de la necesidad de mano de obra, incrementando la cesantía y el hambre. A la sequía se sumaron el pulgón del trigo, la epidemia de fiebre aftosa y las heladas, especialmente perjudiciales para las actividades relacionadas con la vitivinicultura. Así lo hacía ver el senador Castro al Senado al indicar: "por fortuna, mi predio es muy pequeño y no alcanzo a sentir en toda su intensidad los rigores de las heladas, pero estoy consciente, eso sí, porque domino el tema, de que son terribles los perjuicios para el $80 \%$ de los viñateros de nuestro país". Por lo anterior indicaba, "me permito llamar la atención de mis Honorables colegas hacia esta

\footnotetext{
28 Ídem.

29 "La condolencia de un Ministro de Estado", El Labrador, 26 de julio de 1968.

30 Silva, Carlos. 2015. La Gran Sequía de 1968, en Seminario Historia Ambiental, Instituto de Historia, Pontificia Universidad Católica de Chile, Santiago, documento inédito.

${ }^{31}$ Bengoa. 2015. Historia rural de Chile central, p. 294.
} 
situación tan excepcional que azota a la agricultura chilena y que, sumada a los efectos de la sequía, determinará que las actividades vitivinícolas se desarrollen a pérdida, por lo menos durante los próximos tres años" 32 .

Las calamidades climáticas afectarían directamente las actividades productivas y la demanda de mano de obra campesina en un contexto de crisis política y reforma agraria. Los despidos ya se hacían sentir a fines de 1968. Al menos así lo denunciaba la senadora María Elena Carrera, quien señalaba:

"No hace ni tres días, tuve noticias de que un agricultor había despedido veintiún obreros por haberse helado algunas cuadras de su viña. Por eso, deseamos que en el oficio se pida también, junto con las medidas proteccionistas para los agricultores, adoptar otras para defender a los obreros agrícolas, pues no podemos permitir que siga aumentando el número de cesantes que ya hay en el campo a raíz de la sequía. Dejo constancia de que, según estudios realizados durante el último verano, los obreros agrícolas temporales y permanentes que quedarán cesantes sobrepasan los doscientos cincuenta mil. Y si a ello agregamos las heladas en los viñedos, pueden aumentar en gran número los despidos, con lo cual se creará una situación realmente angustiosa, pues hay cientos, miles y decenas de miles de obreros agrícolas chilenos que están trabajando exclusivamente por la comida para él y su familia en obras iniciadas por las intendencias a nivel provincial, y hay otros sin trabajo, que no reciben ninguna remuneración" ${ }^{33}$.

Sin embargo, pese a ser una de las zonas más afectadas, Colchagua no fue incluida en el decreto de zona de catástrofe aprobado por el gobierno, lo cual disminuyó las posibilidades de ayuda del Estado e incrementó el descontento y la sensación de abandono y crisis de los habitantes rurales, los agricultores y la prensa local. Producto de la incertidumbre por la subsistencia familiar se incrementaron las tomas y se intensificó el ambiente conflictivo que existía en el campo chileno ${ }^{34}$.

\section{Las medidas presidenciales, las discusiones en el senado y los efectos políticos de la sequía de 1968}

Frente al denominado "terremoto silencioso», el gobierno de Frei Montalva estableció una entidad especialmente dedicada al problema como fue la Comisión Nacional para la Sequía, dependiente del Ministerio de Agricultura. Asimismo, a fines de 1968, aprobó el Decreto Ley №1474 del Ministerio del Interior que instauró el horario de verano, adelantando en una hora cronológica el reloj en todo el territorio nacional con el objetivo de ahorrar energía y evitar

\footnotetext{
${ }^{32}$ Congreso Nacional de Chile. Diario de Sesiones del Senado, Sesión 7̣, en miércoles 6 de noviembre de 1968, p. 243.

33 Ídem, p. 247.

34 López. 2017. “Un terremoto silencioso”, p. 105.
} 
cortes de electricidad. Ante el Congreso Nacional, el ministro de Agricultura Hugo Trivelli expuso otras medidas que se estaban impulsando y ejecutando. Entre ellas, el gobierno planteaba bonificar los fletes ferroviarios para trasladar miles de animales al sur del país con el objetivo de alimentarlos y evitar su muerte. Además, se había suspendido la importación de ganado, congelado carnes en Magallanes, distribuido alimentos, e iniciado la protección de árboles frutales. Sumado a lo anterior, se había incentivado la construcción de tranques y pozos profundos, los cuales permitirían absorber mano de obra. Adicionalmente, se implementaron otras disposiciones para asegurar el abastecimiento de agua potable, junto con iniciar estudios para determinar el comportamiento del régimen de los flujos de agua de los ríos y la inauguración de plantas termoeléctricas que posibilitaran el suministro de electricidad ${ }^{35}$.

Del mismo modo, la sequía empujó al Servicio Agrícola y Ganadero (SAG) a efectuar una serie de obras de infraestructura de riego, tendientes no solo a solucionar problemas inmediatos causados por la escasez de agua, sino que también a mejorar en forma definitiva el regadío en diferentes zonas del país. En las provincias de Valparaíso y Aconcagua -zona especialmente afectada por la sequía-, bajo la dirección técnica del SAG y mediante el aporte comunitario, se construyeron 20 embalses de acumulación nocturna, con una capacidad de 124.000 metros cúbicos. Igualmente se habilitaron 98 pozos norias y otros tantos pozos someros; 22 pozos profundos alimentadores de canales de regadío y, con la ayuda del Ejército, se encauzó al río Aconcagua en $10 \mathrm{~km}$. Iguales obras se efectuaron en otros ríos de la zona con financiamiento propio de los agricultores. Asimismo, se construyeron en las provincias de Atacama y Coquimbo 12 embalses acumuladores nocturnos; nueve embalses en Choapa; ocho en Coquimbo; cuatro embalses, 30 pozos superficiales y $23 \mathrm{~km}$. de canales en Lampa, Colina y Batuco; 45 tranques y bebederos, con una capacidad de 900.000 metros cúbicos en el área de Melipilla ${ }^{36}$.

Si bien para 1968 no se estimaba una escasez de alimentos, para el año siguiente se calculaba un déficit en la producción de trigo, maíz, lácteos y tabaco. De modo que el Ministerio de Hacienda se encontraba adoptando medidas urgentes para solicitar créditos en el extranjero que permitiesen importar tecnología a fin de combatir la catástrofe ${ }^{37}$. Sin embargo, con el transcurso de los meses todas las medidas parecían insuficientes ante la magnitud de la extraordinaria sequía, que no solo proyectaba carestía de alimentos y falta de empleo, sino que también la agudización de los conflictos sociales y de las exigencias políticas y económicas.

A un mes de iniciado el invierno de 1968, ya se avizoraba en la opinión pública la emergencia climática. El 21 de julio de aquel año, los reporteros de El Mercurio captaron desde un

\footnotetext{
${ }^{35}$ Congreso Nacional de Chile. Diario de Sesiones del Senado, Sesión 30a en viernes 2 de agosto de 1968, p. 1488.

${ }^{36}$ Elizalde, Rafael. 1970. La sobrevivencia de Chile, Santiago de Chile, Ministerio de Agricultura, Servicio Agrícola y Ganadero p. 260.

37 “Déficit de alimentos adicional para 1969 es de US\$ 70.000.000”, La Nación, 7 de agosto de 1968, p. 2.
} 
helicóptero imágenes desoladoras de las áreas rurales de las provincias de Santiago, Aconcagua y Valparaíso, donde "escasos animales deambulaban en los potreros sin pasto, tierras áridas, sin cultivos se suceden unas tras otras" ${ }^{38}$. Los ríos Putaendo, Petorca y Ligua, y los embalses Huechún y La Ligua estaban virtualmente secos. Asimismo, los corresponsales indicaban que, a raíz de la sequía, "los daños se calculan en un mínimo de 600 millones, 300 mil cabezas de ovinos y 12 mil de vacunos ya han perecido por falta de aguas y alimentos. Miles de toneladas de carne y lana se han perdido. Unas treinta mil hectáreas de suelo de la Zona Central destinada a trigo, avena, papas y hortalizas se convirtieron en yermas por falta de agua" ${ }^{39}$.

Luego, el 23 de julio de 1968, el senador del Partido Radical, Hermes Ahumada, planteaba que la carencia de una adecuada reforma agraria, el alza de las tributaciones, el aumento de las imposiciones y el régimen de asentamientos contribuían a la cesantía, pero - a su juicio- el problema se hacía más alarmante "con la sequía que afecta a toda la zona central del país" 40. El gobierno, argumentaba Ahumada, debía estudiar detenidamente la forma de dar solución a este problema, que repercute no solo en las clases obreras y campesinas, con su secuela de pauperización, sino también en la alimentación tanto de las ciudades como en el campo, con la incidencia lógica en la economía nacional”41.

Dos semanas después, en el Congreso Nacional tuvo lugar una discusión en torno a la sequía a raíz de un proyecto presentado por Salvador Allende, presidente del Senado, el cual proponía una prórroga del pago de las contribuciones de bienes raíces y de los impuestos a la renta presunta y global complementaria. Frente a la propuesta, la senadora comunista Julieta Campusano estimó que estas medidas sólo favorecían a los grandes propietarios y que era necesario ir en ayuda del pequeño campesino, que no contaba con acceso a créditos y que no pagaba tales impuestos. Por su parte, el radical Luis Bossay planteó su preocupación por la pérdida de frutales y parronales, pues si se secaban esas plantaciones se necesitarían como mínimo cinco años para recuperar la producción. No obstante, el principal problema analizado era la violencia que se estaba desatando en los campos. El grado de polarización provocado por la Reforma Agraria era intensificado por la escasez de precipitaciones. Se habían producido varios casos de violencia, por ejemplo, en los fundos San Pedro, La Puerta, Quilapán, Longotoma, Longaví y San Miguel en la comuna de San Esteban ${ }^{42}$.

Ante una Reforma Agraria que recién se iniciaba bajo la nueva ley, frente a la falta de alimentos que se hacía sentir por diversos motivos pero que encontraba en la sequía una gran

\footnotetext{
38 "El Mercurio, 21 de julio de 1968. La gran sequía de 1968", En: El Mercurio 22 de julio de 2018.

${ }^{39}$ El Mercurio, 21 de julio de 1968.

${ }^{40}$ Congreso Nacional de Chile. Diario de Sesiones del Senado, Sesión 26ㅁa p. 1174.

41 Ídem.

${ }^{42}$ Congreso Nacional de Chile. Diario de Sesiones del Senado, Sesión 30a․ Sobre la toma del fundo San Miguel véase Pérez, Cristián. 2000. "Guerrilla rural en Chile: La batalla del fundo San Miguel (1968)”, en Estudios Públicos, № 78, Santiago, pp.181-209.
} 
justificación, la senadora socialista María Elena Carrera indicaba ante el Senado que en realidad era posible "apreciar con claridad que todos los chilenos debemos soportar a una clase latifundista inepta que no es capaz de alimentar al país, que no sabe cultivar los campos, como lo demuestran todos los estudios científicos. Todos los chilenos deben pagar de sus bolsillos la inepcia de los terratenientes ${ }^{43 \prime \prime}$.

Por su parte, la senadora Julieta Campusano señalaba que los campesinos estaban siendo humillados y tratados como delincuentes, incluso a través de la prensa. Cuando los diarios habían mostrado a campesinos con sus manos en alto o sobre la nuca como vulgares delincuentes, se le vino a la cabeza -rememoraba- la frase del presidente que quería pasar a la historia como el presidente de los campesinos. A su juicio, era increíble que en tan corto tiempo "Ios hechos, la prepotencia, la dominación de esta clase ensoberbecida, ha hecho que esta frase del presidente Frei Montalva haya pasado a ser solo una palabra" ${ }^{44}$. "No obstante, mientras todo Chile, especialmente las clases populares, se quejan por los efectos de la sequía; mientras hay hambre y miseria; mientras existe el peligro de alza de los precios de todos los artículos de consumo en el país, nos informamos por la prensa de que las ganancias de los bancos continúan siendo fabulosas" ${ }^{45}$.

En este contexto, el senador Tomás Chadwick, representante de la Unión Socialista Popular, se preguntaba: ¿Cómo podía abordarse el problema de los pequeños campesinos, de los animales que mueren, de las familias que deben emigrar, por el simple recurso de otorgar créditos, de rebajar los fletes, de llevar unos cuantos kilos de forraje para el ganado? El senador estaba "seguro de que ninguna de las medidas que se propone adoptar podrá evitar el hambre y la desolación en los campos" ${ }^{\prime 6}$. En consecuencia, a partir de la sequía se había develado y desencadenado "una urgencia que ahora los socialistas populares deseamos poner de relieve: hacer la reforma agraria de inmediato, total, sin ninguna excepción o postergación". Así, el senador estimaba que, ante el "tranco lento que el gobierno ha impreso a la reforma agraria", era necesario acelerarla como una respuesta "a la crisis sobreviniente a la sequía". Por ello, frente a las medidas del gobierno, exigía "profundizar la reforma agraria" ${ }^{47}$. Luego de la intervención de Chadwick, el presidente del Senado, Salvador Allende, pedía:

"Elaborar una política de guerra, en el buen sentido de la palabra. De guerra contra el hambre de los que viven en la desocupación, la que, sin duda, se acrecentará; de guerra para salvar el capital acumulado por el esfuerzo de muchas personas; para, por sobre las diferencias económicas y sociales, salvar al trabajador chileno, sea pequeño, mediano o gran

\footnotetext{
${ }^{43}$ Congreso Nacional de Chile. Diario de Sesiones del Senado, Sesión 30ạ , p. 1475.

${ }^{44}$ Congreso Nacional de Chile. Diario de Sesiones del Senado, Sesión 30å , p. 1490.

45 Ídem.

46 Ídem, p. 1491.

47 Ídem.
} 
propietario, en especial a los más débiles: los campesinos; para proteger efectivamente a miles y miles de nuestros compatriotas que, además de su vida brutalmente oprimida y explotada, se ven enfrentados hoy día a un hecho de proyecciones peligrosísimas, durísimas, para la economía nacional y, fundamentalmente, para el hombre mismo"48.

En este sentido, Salvador Allende respaldó la profundización de la reforma agraria al señalar, "por eso, reitero al señor ministro que estamos atentos para ver de parte del Gobierno la mayor decisión en intensificar, como dijo el Honorable señor Chadwick, el proceso de la reforma agraria, instrumento que puede aplicar sólo el Ejecutivo" ${ }^{49}$. Esta idea se encontraría también en el programa de la Unidad Popular, donde se indicó que los problemas del agro "no los ha resuelto la insuficiente Reforma Agraria del gobierno democratacristiano" 50 .

El 13 de agosto de 1968, el senador Pedro Ibáñez expuso una serie de medidas ideadas por el Partido Nacional para enfrentar la sequía. Entre las principales indicó un plan extraordinario de obras de regadío y créditos agrícolas de fomento ganadero, lechero, avícola, frutícola y forestal, y un plan extraordinario de construcción de viviendas campesinas. Un aspecto importante de la propuesta del Partido Nacional era "evitar el efecto desalentador de la Reforma Agraria en cuanto a las inversiones y mejoras agrícolas", por lo que consideraban que era "indispensable establecer normas especiales que aseguren la pronta y equitativa recuperación de esas inversiones en caso de expropiación de predios" ${ }^{\prime 1}$.

Oponiéndose a tal formulación, para la senadora comunista Julieta Campusano, con estos argumentos se pretendía "hacer de la sequía un pretexto para disminuir el ritmo de la reforma agraria y, sobre todo, debilitar, tanto en la ciudad como en el campo, la lucha de los trabajadores por sus reivindicaciones. Se desea presentar las cosas en forma de que las peticiones y acciones combativas de los trabajadores sean tenidos como actos antipatrióticos en medio de una situación de emergencia nacional" ${ }^{52}$. Los nacionalistas pedían "desde ya sacrificios a quienes son sacrificados diariamente por la explotación de capitalistas o latifundistas. $Y$, por lo contrario, las medidas que se anuncian para aminorar los efectos de la sequía tienden a favorecer precisamente a los poderosos del campo". A su juicio, a los latifundistas en estos momentos la sequía les venía "de perilla", pues les permitía propiciar condonaciones indiscriminadas de impuesto y "también circula la idea de rebajar los aportes del servicio de seguro social, cuando han sido ellos quienes han burlado siempre las imposiciones, llenando a los campos con ancianos que luego de una vida de trabajo no han

\footnotetext{
48 Ídem, p. 1493.

49 Ídem.

50 Programa básico de gobierno de la Unidad Popular: candidatura presidencial de Salvador Allende, Santiago, 1970, p. 9.

${ }^{51}$ Congreso Nacional de Chile. Diario de Sesiones del Senado, Sesión 33모, en martes 13 de agosto de 1968, p. 1708.

52 Ídem, p. 1722.
} 
tenido como premio ni siquiera el goce de la miserable pensión de vejez" ${ }^{53}$. La sequía debía ser enfrentada entonces "sin pensar en frenar la reforma agraria sino todo lo contrario: encaminando todos los esfuerzos a asegurar su aceleramiento" ${ }^{54}$.

Así, la sequía ponía en evidencia la polarización política, pero también los problemas de fondo que estaba teniendo el proceso de reforma agraria en un contexto de escasez hídrica. Históricamente, el manejo de las aguas de riego ha constituido una de las materias más conflictivas del medio rural. Más aún, en un contexto de escasez de precipitaciones, el agua siguió siendo un campo de disputa y poder en el cual los campesinos salieron desfavorecidos, pese a los esfuerzos políticos y técnicos realizados en torno a la gestión de los derechos de agua; como por ejemplo una reforma constitucional, la modernización de los organismos públicos competentes, el establecimiento de mecanismos técnicos de asignación del agua, obras de riego y la creación de una Empresa Nacional de Riego ${ }^{55}$.

Por ejemplo, en la Cooperativa Presidente Kennedy, los resultados de las cosechas habían sido bastante malos al no existir disponibilidad de agua para riego suficiente ya que se habían entregado las parcelas sólo con un 50\% de riego, por lo que la sequía de 1968 afectó enormemente la productividad de esta asociación. En consecuencia, las "condiciones económicas en que se hallan los pequeños propietarios en este instante son prácticamente deplorables". Había que reconocer, entonces, que con el afán de dar cumplimiento al programa de reforma agraria, se entregaban terrenos sin todos los elementos necesarios para que los nuevos pequeños propietarios de tierras pudieran desarrollar sus actividades productivas ${ }^{56}$.

Otro ejemplo lo constituye la Colonia Agrícola Santa Fe, donde los terrenos habían sido entregados de forma precipitada, sin caminos, puentes y cercos, ni tampoco con las obras de regadío correspondientes, de modo que se había convertido en un problema gravísimo a partir de la sequía ${ }^{57}$. Por su parte, la senadora Campusano denunciaba que "las aguas de los tranques del Departamento de Ovalle estaban siendo utilizadas por los latifundistas" ${ }^{58}$. En las estancias de secano afectadas "la gente no tiene qué comer. Se han muerto los animales. No han tenido cosechas ni en el pasado ni en el presente. Están debiendo los arrendamientos" ${ }^{59}$.

¿Fue, entonces, la sequía un factor que frustró las expectativas, arruinó la producción agrícola, agudizó los conflictos en los campos y radicalizó las polarizadas posiciones políticas? De acuerdo con los planteamientos ya vistos, en ocasiones se entregaron parcelas, pero no

\footnotetext{
53 Ídem, p. 1723.

54 Ídem, p. 1708.

55 Moreno, Rafael. 2014. Sin Reforma Agraria no habría sido posible: Memorias de la Reforma Agraria chilena 19581970, Santiago, Ed. Copygraph, pp. 219-220.

${ }^{56}$ Congreso Nacional de Chile. Diario de Sesiones del Senado, Sesión 55ạa, en miércoles 7 de mayo de 1969, p. 3709.

57 Ídem, p. 3716.

${ }^{58}$ Congreso Nacional de Chile. Diario de Sesiones del Senado, Sesión 30a , p. 1490.

${ }^{59}$ Congreso Nacional de Chile. Diario de Sesiones del Senado, Sesión 55ạ , p. 3731.
} 
disponibilidad de agua, cuestión que deja en evidencia las dificultades que enfrentaba una reforma agraria que coincidía con un período de sequía extrema que implicaba la pérdida de cosechas por falta de riego y de lluvias. La escasez de precipitaciones pudo haber mermado las expectativas del incipiente movimiento campesino, más también el acceso a alimentos de los habitantes urbanos. Por otro lado, las condiciones económicas de los numerosos pequeños agricultores eran realmente desastrosas por la pérdida de las cosechas, de los animales y de las fuentes de trabajo.

Por su parte, los grandes agricultores, agrupados en la Sociedad Nacional de Agricultura y en el Partido Nacional, estimaban que el gobierno demócrata cristiano había implementado medidas lesivas para la agricultura. Por ejemplo, el diputado Fernando Ochagavía afirmaba que "entregar a un organismo estatal la determinación de la cuota de riego necesaria para un predio era un expediente arbitrario de profunda perturbación" ${ }^{60}$. Asimismo, el gobierno había establecido que aquellos empleadores que despidieran obreros por la sequía sin usar los créditos oficiales disponibles podían ser expropiados ${ }^{61}$. En respuesta, los propietarios apoyados por la Sociedad Nacional de Agricultura y por el Partido Nacional fundaron la Confederación de Sindicatos de Empleadores de Chile (CONSEMACH) ${ }^{62}$. El presidente de la Sociedad Nacional de Agricultura, Hugo Zepeda, sintetizaba de modo elocuente el sentir de los grandes agricultores al señalar:

"cinco graves problemas están penando en la agricultura chilena. Hay desconfianza en los agricultores por la Reforma Agraria. Existe una baja alarmante en la rentabilidad de la agricultura por falta de precios adecuados. Además, la restricción del crédito bancario sumado a las terribles heladas y sequías resume la aflictiva situación actual. Se acabaron los tiempos en que se podía vivir tranquilamente de las rentas del campo. Nadie trabajaba por amor al arte y menos aún con pérdidas"63.

En virtud del análisis desarrollado en este trabajo, podemos establecer que la sequía contribuyó a frustrar las esperanzas y a exacerbar la violencia en los campos, extremando las posturas sociopolíticas. Frente a la catástrofe, hubo diversas propuestas para mitigar los impactos económicos y sociales ocasionados por la sequía, pero los impactos del "terremoto silencioso" habían golpeado con fuerza a diversos actores políticos, económicos y sociales. En este contexto, es posible plantear que la sequía tuvo un grado importante de influencia en la

\footnotetext{
${ }^{60}$ Avendaño, Octavio. 2017. Los partidos frente a la cuestión agraria en Chile, 1946-1973: Representación de intereses, gradualismo y transformación estructural, Santiago, LOM Ediciones, p. 274.

61 Oszlak, Oscar. 2016. La trama oculta del poder. Reforma agraria y comportamiento político de los terratenientes chilenos, 1858-1973, Santiago, LOM Ediciones, p. 230.

62 Redondo, Jesús Ángel. 2017. Tierra, trabajo y libertad. Conflictos campesinos e indígenas en la provincia de Cautín (1967-1973), Santiago, LOM Ediciones, p.130.

${ }^{63}$ Moreno. 2014. Sin Reforma Agraria, p. 316.
} 
aceleración de los conflictos y en los resultados de las elecciones de 1970. Especialmente porque el deterioro de las condiciones de vida de los campesinos, la disposición de alimentos y los puestos de trabajo urbanos se vieron seriamente afectados por la sequía de 1968 que, para efectos prácticos, se prolongó hasta buena parte de 1969.

\section{Consideraciones finales}

Una vez analizado el contexto sociopolítico y económico de la década de 1960 y las fuentes que nos remiten a la sequía de 1968, a las discusiones y medidas parlamentarias y de gobierno, junto a los efectos catastróficos de este fenómeno climático en el ámbito rural ya afectado por el proceso de reforma agraria- y en el ámbito urbano al plantear el problema de la escasez de energía y alimentos-, es posible plantear que la falta de precipitaciones fue un factor importante en la agudización de la crisis sociopolítica del período y en el resultado de la elección presidencial de 1970.

En sus discursos, el Presidente Eduardo Frei Montalva aseguraba que su gobierno había sido afectado por un "terremoto silencioso", intentando de algún modo representar o comunicar a la ciudadanía la magnitud de la catástrofe cuyos efectos se imbricaban con los procesos y conflictos sociopolíticos que afectaban a su gobierno. No obstante, sin temor a equivocarnos, podemos decir que este factor no sólo ha sido minimizado en los análisis sobre los procesos históricos del período, sino que tampoco ha sido visibilizado ni menos considerado. La escasez de un elemento tan vital como el agua es sin duda un factor de conflicto sociopolítico, en tanto lo entendemos no solo como el elemento natural que es, sino también a partir de todas las relaciones sociopolíticas y económicas y efectos que genera tanto su uso como su distribución, y por lo tanto como un hecho histórico y cultural.

En las últimas décadas, la naturaleza como problema histórico ha adquirido gran relevancia frente a la crisis socio ecológica contemporánea, incluso en América Latina ${ }^{64}$. ¿Es la naturaleza un mero telón de fondo de las acciones humanas? Sin caer en un determinismo geográfico, la historia muestra nuestra vulnerabilidad frente al entorno ${ }^{65}$. Más que pretender que en el clima

\footnotetext{
${ }^{64}$ Gallini, Stefania. 2020. «¿Qué hay de Histórico en la Historiografía ambiental en América Latina?.», en Historia y Memoria, ํㅡㄹ Especial, pp.179-233. Sánchez-Calderón, Vladimir y Jacob Blanc. 2019. "La historia ambiental latinoamericana: cambios y permanencias de un campo en crecimiento", en Historia Crítica, N ${ }^{\circ} 74$, Bogotá, pp.3-18. Leal, Claudia. 2005. "Presentación del dossier sobre historia ambiental latinoamericana", en Historia Crítica, N ³0, Bogotá, pp.5-11. Ortega Santos, Antonio. 2012. "Introducción al dossier de historia ambiental latinoamericana. Las necesidades y capacidades de la historia ambiental latinoamericana. Agenda de trabajo y propuestas epistémicas" Historia Agraria, $\mathrm{N}^{\circ}$ 56. Leal, Claudia. 2019. "Aguzar la mirada colectiva, el gran desafío de la historia ambiental latinoamericana." Historia y Sociedad. Medellín, Colombia.

65 Entre muchos ejemplos véanse: Latour, Bruno. 2017. Cara a cara con el planeta Una nueva mirada sobre el cambio climático alejada de las posiciones apocalípticas. Buenos Aires, Siglo XXI. Chakrabarty, Dipesh. 2019. "El clima de la Historia: Cuatro tesis". En: Utopía y Praxis Latinoamericana; Año 24, N ${ }^{\circ} 84$ (enero-marzo). Locher, Fabien, et Grégory Quenet. 2009. "L'histoire environnementale: origines, enjeux et perspectives d'un nouveau chantier», En: Revue d'histoire moderne \& contemporaine, vol. 56-4, $N^{\circ} 4$. Torres, Alberto Martín. 2020. "El impacto de la Historia
} 
residiría la explicación de los fenómenos y dinámicas sociales, se trata de no ignorar que este factor puede ser un factor explicativo al menos por considerar ${ }^{66}$.

En medio de una reforma agraria en curso, era importante reformar la tenencia de la tierra pero quizás más la del agua, pues la tierra sin agua evidentemente no tiene el mismo valor productivo. En efecto, el gobierno de Frei Montalva logró modificaciones importantes en la codificación del agua, lo cual agudizó todavía más las pérdidas de los agricultores, sobre todo en medio de una de las sequías más grandes de la historia nacional. Así como los agricultores perdían derechos de agua y riqueza, los campesinos afectos a la reforma agraria solicitaban mayores derechos sobre un recurso que en aquel año escaseaba en forma dramática. Había además alarma por la escasez de energía y alimentos. Todo ello bien pudo ser un factor más en la agudización de los conflictos y en los resultados de la elección presidencial de 1970. En suma, la sequía de 1968 constituye un evento climático que interactúa con su contexto histórico y que se configura como un elemento precipitante que afectó no sólo la producción agrícola nacional, sino que al mismo tiempo agudizó los conflictos sociales, políticos y económicos del período.

\section{Referencias citadas}

\section{Fuentes}

El Labrador. 1968. Melipilla.

El Mercurio. 1968. Santiago.

Topaze. 1968. Chile.

Congreso Nacional de Chile. 1968. Diario de Sesiones del Senado, Sesiones $7 \stackrel{a}{\underline{a}}, 24 \underline{a}, 26 \underline{a}$, y $30 \stackrel{a}{d e}$ 1968.

Congreso Nacional de Chile. 1969. Diario de Sesiones del Senado, Sesiones $17 \underline{a}$ y $55 \underline{a}$ de 1969. Sexto Mensaje Presidencial de S.E. Don Eduardo Frei Montalva al inaugurar el periodo de Sesiones Ordinarias del Congreso Nacional, 21 de mayo de 1970. 1970. Santiago, Presidencia de la República, Departamento de Publicaciones.

Programa básico de gobierno de la Unidad Popular: candidatura presidencial de Salvador Allende, Santiago, 1970.

\footnotetext{
Ambiental en la historiografía actual española (2010-2019)". Revista de historiografía N 33. Winiwarter, Verena, Marco Armiero, Petra Van Dam, Andreas Dix, Per Eliasson, Poul Holm, Leos Jeleček, Robert A Lambert, Genevieve Massard-Guilbaud, Manuel Gonzales de Molina, Timo Myllyntaus, Jan Oosthoek, Christian Pfister, Lajos Racz. 2004. "Environmental history in Europe from 1994 to 2004: enthusiasm and consolidation". En: Environment and History $\mathrm{N}{ }^{\circ} 10$. Arnold, David. 2000. La naturaleza como problema histórico: El medio, la cultura y la expansión de Europa. México, Fondo de Cultura Económica.

66 Mora, Katherinne. 2020. "Tras la pista de "terribles veranos" y "copiosas lluvias". Elementos para una historia climática del territorio colombiano". Historia Crítica, $\mathrm{N}^{\circ} 74$.
} 


\section{Bibliografía}

Abadía Quintero, Carolina y Echeverry Pérez, Antonio. 2020. De mayo del 68 a la Cali del 70. Ensayos en perspectiva latinoamericana de una década que transformó al mundo, Cali, Colombia, Programa Editorial UNIVALLE.

Adorno, Theodor y Horkheimer, Max. 1998. Dialéctica de la llustración: fragmentos filosóficos, Madrid, España, Trotta.

Arnold, David. 2000. La naturaleza como problema histórico: El medio, la cultura y la expansión de Europa, Ciudad de México, Fondo de Cultura Económica.

Avendaño, Octavio. 2017. Los partidos frente a la cuestión agraria en Chile, 1946-1973: Representación de intereses, gradualismo y transformación estructural, Santiago de Chile, LOM Ediciones.

Bengoa, José. 2015. Historia rural de Chile central: Tomo II. Crisis y ruptura del orden hacendal, Santiago de Chile, LOM Ediciones.

Bengoa, José. 2016. Reforma agraria y revuelta campesina: seguido de un homenaje a los campesinos desaparecidos, Santiago de Chile, LOM Ediciones.

Canales, Manuel, Razeto, Jorge y Valenzuela, René (coord.). 2018. Casta y sumisión: Chile a 50 años de la Reforma Agraria, Santiago de Chile, Social Ediciones.

Collier, Simon y Sater, William. 1999. Historia de Chile, Madrid, España, Cambridge University Press.

Consejo Asesor Campesino. 2018, Con nuestra letra: relatos campesinos de la Reforma Agraria chilena escritos por puño y letra de sus protagonistas, Santiago de Chile, Consejo Asesor Campesino, Región Metropolitana, INDAP.

Correa, Sofía (et al.). 2001. Historia del siglo XX chileno, Santiago de Chile, Editorial Sudamericana. Chonchol, Jacques (et al.). 2017. Reforma agraria, Santiago de Chile, Editorial Aún Creemos en los Sueños.

Cunill, Pedro. 1971. Geografía de Chile, Santiago de Chile, Editorial Universitaria.

Chakrabarty, Dipesh. 2019. "El clima de la Historia: Cuatro tesis", en Utopía y Praxis Latinoamericana, Año 24, № 84 (enero-marzo), Venezuela, pp. 98-118.

Elizalde, Rafael. 1970. La sobrevivencia de Chile, Santiago de Chile, Ministerio de Agricultura, Servicio Agrícola y Ganadero.

Gac, Daniella; Flores, Daniel; Thezá, Marcel. 2017. "Reformas agrarias en América Latina y Chile: lecciones aprendidas sobre la controversia de la propiedad de la tierra". Polis, Revista Latinoamericana, № 47, Santiago, pp. 5-11.

Gallini, Stefania. 2020. “¿Qué hay de Histórico en la Historiografía ambiental en América Latina?”, en Historia y Memoria, N Especial, Boyacá, pp. 179-233.

Gazmuri, Cristián (et al.). 1996. Eduardo Frei Montalva: (1911-1982), Ciudad de México, Fondo de Cultura Económica.

Góngora, Mario. 1985. Ensayo histórico sobre la noción de Estado en Chile en los siglos XIX y XX, Santiago de Chile, Editorial Universitaria. 
Latour, Bruno. 2017. Cara a cara con el planeta Una nueva mirada sobre el cambio climático alejada de las posiciones apocalípticas, Buenos Aires, Argentina, Siglo XXI.

Leal, Claudia. 2005. "Presentación del dossier sobre historia ambiental latinoamericana", Historia Crítica, №30, Bogotá, pp. 5-11.

Leal, Claudia. 2019. "Aguzar la mirada colectiva, el gran desafío de la historia ambiental latinoamericana", en Historia y Sociedad, Nㅜ 36, Medellín, pp. 243-268.

Locher, Fabien y Quenet, Grégory. 2009. "L'histoire environnementale: origines, enjeux et perspectives d'un nouveau chantier", en Revue d'histoire moderne \& contemporaine, vol. 56, $\mathrm{N}^{\circ}$ 4, Paris, pp. 7-38.

López, Nicolás. 2017. "Un terremoto silencioso. Sequía y crisis social en el campo chileno, 19671969", en Seminario Simon Collier 2017, Instituto de Historia, Pontificia Universidad Católica de Chile, 2017.

Mora, Katherinne. 2019. "Tras la pista de "terribles veranos" y "copiosas lluvias". Elementos para una historia climática del territorio colombiano", en Historia Crítica, № 74, Bogotá, pp. 19-40.

Moreno, Rafael. 2014. Sin Reforma Agraria no habría sido posible: Memorias de la Reforma Agraria chilena 1958-1970, Santiago de Chile, Editorial Copygraph.

Olea Peñaloza, Jorge. 2017. "Latifundio y territorio: reflexiones en torno a la reforma agraria en Colchagua, 1960-1973”, en Polis, Revista Latinoamericana, № 47, Santiago, pp. 83-106.

Ortega Santos, Antonio. 2012. "Introducción al dossier de historia ambiental latinoamericana. Las necesidades y capacidades de la historia ambiental latinoamericana. Agenda de trabajo y propuestas epistémicas", en Historia Agraria, №56, Murcia, pp. 77-79.

Oszlak, Oscar. 2016. La trama oculta del poder. Reforma agraria y comportamie nto político de los terratenientes chilenos, 1858-1973, Santiago de Chile, LOM Ediciones.

Pellegrini, Mario. 2008. La imaginación al poder, Buenos Aires, Argentina, Argonauta.

Pérez, Cristián. 2000. "Guerrilla rural en Chile: La batalla del fundo San Miguel (1968)", en Estudios Públicos, N 78, Santiago, pp. 181-209.

Reyes Del Villar, Soledad. 1999. La Revolución Cultural de los años 60' vista a través del Mayo Francés y del Movimiento Estudiantil Chileno. Instituto de Historia Universidad Católica, Santiago de Chile, Tesis Licenciatura en Historia.

Rojas, Álvaro y Manríquez, Paula (Eds.). 2017. Reforma agraria 50 años después: origen y desarrollo del proceso, Talca, Chile, Editorial Universidad de Talca.

Sagredo, Rafael. 2014. Historia mínima de Chile, Madrid, España, Turner Publicaciones S.L.

Salazar, Gabriel y Julio Pinto. 2014. Historia contemporánea de Chile, Santiago de Chile, LOM Ediciones.

Sánchez-Calderón, Vladimir y Blanc, Jacob. 2019. "La historia ambiental latinoamericana: cambios y permanencias de un campo en crecimiento", en Historia Crítica, Nㅜ 74, Bogotá, pp. 3-18.

Seidman, Michael. 2018. La Revolución Imaginaria. París 1968: Estudiantes y Trabajadores en el Mayo Francés, Madrid, España, Alianza Editorial. 
Servan Schreiber, Jean Jacques. 1968. El despertar de Francia. mayo-junio 1968, Barcelona, España, Plaza \& Janés.

Silva, Carlos. 2015. “La Gran Sequía de 1968”, en Seminario Historia Ambiental, Instituto de Historia, Pontificia Universidad Católica de Chile, documento inédito, pp. 15.

Ramón, Armando de. 2015. Historia de Chile: desde la invasión incaica hasta nuestros días (15002000), Santiago de Chile, Catalonia Ltda.

Redondo, Jesús Ángel. 2017. Tierra, trabajo y libertad. Conflictos campesinos e indígenas en la provincia de Cautín (1967-1973), Santiago de Chile, LOM Ediciones.

Torres Dujisin, Isabel. 2009. "La década de los sesenta en Chile: la utopía como proyecto", Historia Actual Online, №19, Cádiz, pp. 139-149.

Winiwarter, Verena, Marco Armiero, Petra Van Dam, Andreas Dix, Per Eliasson, Poul Holm, Leos Jeleček, Robert A Lambert, Genevieve Massard-Guilbaud, Manuel Gonzales de Molina, Timo Myllyntaus, Jan Oosthoek, Christian Pfister y Lajos Racz. 2004. "Environmental history in Europe from 1994 to 2004: Enthusiasm and consolidation”. Environment and History, №10, Oxford, pp. 501-530. 